\title{
The Rumsfeld Paradigm: Knowns and Unknowns in Characterizing Habitats Used by the Endangered Sharp-tailed Snake, Contia tenuis, in Southwestern British Columbia
}

\author{
Shannon F. Wilkinson ${ }^{1,4}$, Patrick T. Gregory ${ }^{1,5}$, Christian EngelstofT ${ }^{2}$, and Kari J. Nelson ${ }^{3}$ \\ ${ }^{1}$ Department of Biology, University of Victoria, P.O. Box 3020 STN CSC, Victoria, British Columbia V8W 3N5 Canada \\ ${ }^{2}$ Alula Biological Consulting, 1967 Nicholas Road, Saanichton, British Columbia V8M 1X8 Canada \\ ${ }^{3}$ Ecosystems Branch, British Columbia Ministry of Environment, P.O. Box 9338 STN PROV GOVT, Victoria, British \\ Columbia V8T 5J9 Canada \\ ${ }^{4}$ Present Address: 824 Leslie Drive, Victoria, British Columbia V8X 2Y4 Canada \\ ${ }^{5}$ Author for correspondence: viper@uvic.ca
}

Wilkinson, Shannon F., Patrick T. Gregory, Christian Engelstoft, and Kari J. Nelson. 2007. The Rumsfeld paradigm: knowns and unknowns in characterizing habitats used by the endangered Sharp-tailed Snake, Contia tenuis, in southwestern British Columbia. Canadian Field-Naturalist 121(2): 142-149.

The Sharp-tailed Snake, Contia tenuis, has a small and highly fragmented range in British Columbia, where it is considered endangered. Known sites are few in number and generally small in spatial extent; numbers of snakes apparently are correspondingly low. Furthermore, most known sites for the species are on private lands in areas that are fairly heavily developed or being developed. Thus, the species is under serious threat of habitat alteration or loss. Although land stewardship has been a valuable conservation tool in this case, we also need to identify the key habitat requirements of Sharp-tailed Snakes to identify potential new sites, modify former or potential ones, or even create new ones. In this study, we compared sites known to harbour Sharptailed Snakes with those that seemed subjectively similar and therefore potentially suitable. We also compared these known and potential sites with randomly chosen nearby locations. Variability of most measured features was high, both within and among site/location categories. Nonetheless, we found significant differences between known and potential sites and between those locations and random ones. Overall, locations known to be used by snakes had a more southerly aspect, more rock cover, shallower soil and litter, and less shrub cover than other sites. This study was constrained by the small number of known sites for Sharp-tailed Snakes in southwestern British Columbia, making our conclusions suggestive rather than definitive. Future work should incorporate additional variables. It also might be useful to undertake comparative habitat studies elsewhere in the range of the Sharp-tailed Snake where it is more common.

Key Words: Sharp-tailed Snake, Contia tenuis, habitat, British Columbia.

On 12 February 2002, U.S. Secretary of Defense Donald Rumsfeld made the following widely cited observation:

"As we know, there are known knowns; there are things we know we know. We also know there are known unknowns; that is to say, we know there are some things we do not know. But there are also unknown unknowns, the ones we don't know we don't know. And if one looks throughout the history of our country and other free countries, it is the latter category that tend to be the difficult ones."

Although Rumsfeld was not discussing science, his circumlocutional comments nonetheless may well be apt in science (Shermer 2005). In conservation biology, the unknowns, whether known or unknown, usually exceed the known knowns and we often have to make educated guesses in, for example, trying to determine where there might be additional suitable habitats for a threatened or endangered species.

To manage and conserve any species, it is crucial to understand its habitat requirements. The fitness of any species should be greatest in a habitat for which it is best suited and that it presumably prefers (Garshelis 2000). Determining critical habitats is an important component of the background knowledge that allows researchers and managers to develop strategies to either recover or maintain an endangered or threatened species and to choose areas in which to explore such strategies.

The Sharp-tailed Snake (Contia tenius) is a small secretive snake, from 20 to $45 \mathrm{~cm}$ in total length when adult (Leonard and Ovaska 1998), that ranges from southern California to southern British Columbia (Cook 1960). Although the southern part of its range, to northern Oregon, is more-or-less continuous, the distribution of this species is highly fragmented in Washington and British Columbia (Leonard and Ovaska 1998). In British Columbia, Sharp-tailed Snakes are known only from a small number of scattered locations on southern Vancouver Island and some of the adjacent Gulf Islands. A previous report from Chase in the interior of British Columbia is of doubtful origin (Matsuda et al. 2006). Because of the low numbers of snakes found in Canada and few known sites, the snake was considered an endangered species by COSEWIC in 1999 (COSEWIC 2002*). Although formal study of Sharptailed Snakes has been limited, recent studies done in British Columbia and adjacent Washington cover aspects of their ecology such as defensive behaviour (Ovaska and Engelstoft 1999; Leonard and Stebbins 1999), aggregative behaviour (Leonard et al. 1996), 
movements (Engelstoft et al. 1999), habitat (Leonard and Leonard 1998), and cover use (Engelstoft and Ovaska 2000).

Most of the areas where the Sharp-tailed Snake is found in British Columbia have fairly dense human populations and highly disturbed habitat. Consequently, many of the sites at which snakes are found are on private land. Although the Sharp-tailed Snake seems somewhat tolerant of anthropogenic habitat disturbance, habitat loss is still considered the primary threat to its persistence in Canada. Therefore, management and stewardship by landowners are important factors in conservation programs for this species.

The aim of this study was to determine the key characteristics that define habitats used by the Sharp-tailed Snake, in order to guide future habitat management. We did this by comparing sites known to be used by Sharp-tailed Snakes with sites that were subjectively similar but not known to be used (potential sites), and with locations chosen at random with respect to both known and potential site types. The first comparison objectively tested whether potential sites actually are similar to those sites known to be used by these snakes and the second tested whether Sharp-tailed Snakes use a subset of those habitats that are available. Initial observations suggested that south-facing rocky slopes and forest clearings appeared to provide the most suitable habitat for this species (see also Leonard and Leonard 1998), but no quantitative assessment of habitat characteristics has previously been done. Thus, we measured a wide range of possibly influential habitat variables at each sample location and compared them statistically among locations.

Although our comparisons among sites and locations were objective, selection of potential sites obviously was biased by our general knowledge of snake ecology and our previous experience with Sharp-tailed Snakes. This mainly reflected an aim of the recovery program for this species to find as many occupied sites as possible.

\section{Study Area}

In the past few years, federal lands in the Capital Regional District (including Gulf Islands National Park, Department of National Defence lands, and Coast Guard properties) have been assessed and rated for suitability as habitat for the Sharp-tailed Snake (Engelstoft and Ovaska 1998*). These sites are in various locations on North and South Pender Islands, Saltspring Island and southern Vancouver Island. In addition, artificial cover objects (ACOs) have been installed at all sites at which Sharp-tailed Snakes are known to occur, including private lands, and at sites rated as having high potential as habitat for these snakes. ACOs provide easily sampled, attractive cover and, combined with naturally occurring cover objects, are an effective means of determining presence of snakes (Engelstoft and Ovaska 2000). Sharp-tailed Snakes are secretive

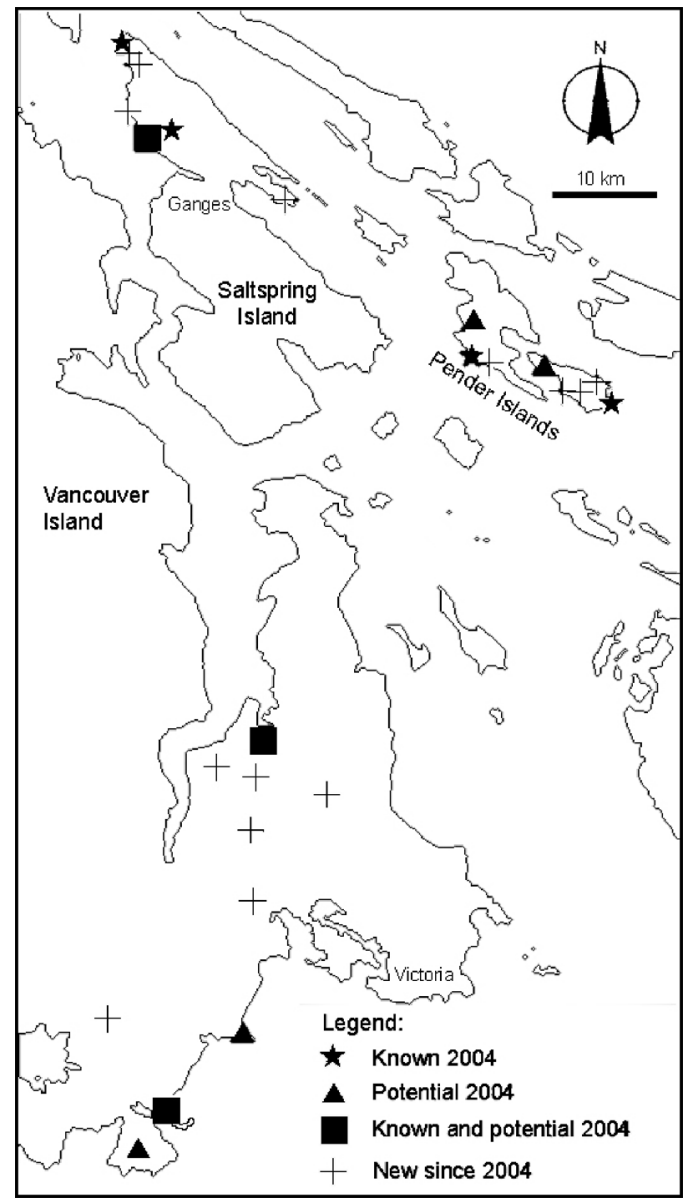

FIGURE 1. Map of study area with sites known to be occupied by Sharp-tailed Snakes up to 2004 and since, and potential sites identified in 2004. Squares labeled "known and potential 2004" indicate known and potential sites that are too close together to represent separately on this map. For reference, latitude and longitude for Victoria are $48^{\circ} 25^{\prime} \mathrm{N}$ and $123^{\circ} 19^{\prime} \mathrm{W}$, respectively, and for Ganges $48^{\circ} 51^{\prime} \mathrm{N}$ and $123^{\circ} 31^{\prime} \mathrm{W}$, respectively. Modified from a map obtained from the Natural Areas Atlas on the Capital Regional District (2008*) website.

and rarely seen in the open, and ACOs provide the main means by which they are discovered in the field. Potential sites in this study were identified by CE based on his extensive field experience with Sharp-tailed Snakes.

The sites where ACOs have been placed can be classified into two general types. Unrestricted sites are those with relatively large extents of contiguous habitat under the same ownership surrounding the location of the ACO. These areas typically have experienced relatively little disturbance in the last century (e.g., Department of National Defence lands or Canada Parks lands). Restricted sites are those on relatively 
small, privately owned properties surrounded by private lands in relatively developed areas. These locations have generally experienced a greater degree of habitat modification (buildings, roads, gardens, etc.).

\section{Methods}

Fieldwork for this study was undertaken in summer and autumn of 2004. Our general sampling scheme was straightforward. The 31 sites were divided into two site types, those known to harbour Sharp-tailed Snakes (known knowns) and those that appeared to have the potential to harbour them (known unknowns). Hereafter, we call these known and potential sites, respectively (Figure 1). At each of these sites, in addition to the known or potential assigned location, we also chose a corresponding random location (unknown unknowns) for sampling. Random locations were $50 \mathrm{~m}$ from an assigned location, but in a randomly chosen direction. Because $50 \mathrm{~m}$ was well within the known movement capabilities of Contia (Engelstoft et al. 1999), yet far enough away for the environment to vary significantly, this distance provided a test of non-random use of the local habitat. However, because most known sites are restricted, we were able to obtain a random location for only seven of the 16 known sites (compared to $14 / 15$ for potential sites). Our sampling protocol was thus dictated to a large degree by access to private property, and by the amount of contiguous habitat under the same ownership surrounding the site. The total number of assigned and random locations at all sites combined was 52. At each of these locations, we took samples along three randomly chosen $10-\mathrm{m}$ long transects.

The first transect at each assigned location was placed in a random direction from a randomly chosen $\mathrm{ACO}$, so that the $0-\mathrm{m}$ mark was at the centre of the ACO. The other two transects were placed at two different randomly chosen locations (and in random directions) within a $25-\mathrm{m}$ radius of the initial ACO. We measured canopy cover, aspect, and slope of location at the 0-m mark of the first transect; that is, these variables were measured once per location. All other variables were measured along each of the three transects (i.e., three replicates for each location). This same protocol was repeated for random locations, with a point on the ground standing in for an ACO. We ensured that transects around an assigned location and its associated random location did not overlap or abut each other.

We measured the following variables at each of the 52 locations:

1. Percentage canopy cover - Canopy cover was measured once for each location at the starting point of the first transect, directly overhead, and then at a $45^{\circ}$ angle in each of the cardinal directions (south, north, east and west surrounding canopy cover). The tree species making up the canopy cover also were recorded.

2. Aspect - The aspect of each location was measured in degrees using a compass at the starting point of the first transect. A measurement of $180^{\circ}$ indicates a southerly aspect.

3. Slope - The general slope of the location was recorded in degrees as well as the slope for each separate transect. Both were measured using a compass equipped with a clinometer.

4. Substrate - At the 1-m mark along each transect, we determined the depth of both soil and litter layer by measuring the distance a thick wire penetrated into the ground. The composition of the litter (needles, leaves, etc.) also was recorded.

5. Rock coverage - Rock coverage was determined at each transect by measuring the total distance intercepted by rocks along the length of the transect. The rocks were rated by size as follows: loose gravel (pebbles $<7.5 \mathrm{~cm}$ ), cobbles $(7.5-19.9 \mathrm{~cm})$, rocks $(20-50 \mathrm{~cm})$, boulders $(>50$ $\mathrm{cm})$, and bedrock.

6. Coarse woody debris - This was determined by measuring the total distance intercepted by coarse woody debris along the transect. Each piece of coarse woody debris was identified to species (if possible), and assigned a decay class (1-5) as per Table 5.13 in Meidinger (1998*).

7. Vegetation - Shrub cover and ground cover were determined by measuring the total distance intercepted by vegetation along the transect. For logistical reasons, coverage by each of lichens, bryophytes, grass and forbs was expressed as the total distance intercepted by these plants between the 2-m and 4-m marks of each transect.

\section{Statistical Analyses}

We used SAS 8.0 to analyze the data, except for aspect, which we also analyzed using ORIANA software. We compared locations and site types using both univariate and multivariate statistics. Although one level of the factor "location" was a randomly selected partner to a known or potential assigned location for Sharp-tailed Snakes, all factors (site, site type, location) were treated as fixed factors because all sites initially were chosen deliberately as particular site types and locations. In cases of non-orthogonal data, we used Type III sums of squares for F-tests. As this was essentially an exploratory study, we used a liberal criterion for tests of significance, highlighting all results for which $P<0.10$.

Most variables showed no clear pattern of heterogeneity among categories of sites, so we combined them in various ways, which also reduced the number of variables to manageable levels, as follows: total shrub coverage (all shrubs - e.g., broom, Oregon grape, salal); tall, non-shrub coverage (ferns and asters); thick ground cover (e.g., ivy, periwinkle, trailing blackberry); light ground cover (lichens, bryophytes, grasses, forbs); rock cover (sum of all rock-size classes); coarse woody debris (sum of all CWD decay classes); and surrounding canopy cover (average of directional values around sample location). All other variables (e.g. overhead canopy cover, soil depth, slope) were left unaltered.

Because assigned and random locations were paired at unrestricted sites, we compared them via a 2-way factorial analysis of variance (ANOVA), with the three transects treated as replicates within each combination 
of site and location. We did this analysis separately for known and potential site types, as they were in different places. In each case, we had to drop restricted sites from the analysis because they lacked a random location. In all cases in which the interaction between factors was non-significant, we dropped it from the analysis to test main factors only. In cases in which the interaction was significant, compromising interpretation of main effects, we then did a comparison of locations for each site separately.

To compare known and potential site types, we used a nested ANOVA (sites nested within site type), analyzing assigned and random locations separately, with transects serving as replicates within locations. F-tests were adjusted to those appropriate for nested ANOVA (Sokal and Rohlf 1981).

Because aspect is an angular variable, with the lowest possible value $\left(0^{\circ}\right)$ identical to the highest possible $\left(360^{\circ}\right)$, we treated it differently from the other variables. We categorized aspect at each location as one of four quadrants representing the four cardinal directions and then compared frequency of directions among site type/location categories (known/assigned, known/random, potential/assigned, potential/random) by contingency-table analysis. We also used circular (angular) statistics, as described by Zar (1984), to compare mean aspect between pairs of site type/location categories.

In addition to aspect, a few other variables (e.g. canopy cover) were recorded only once for each location, rather than separately for each transect. We therefore reduced the data set to average values for each location and then analyzed those new variables using twoway ANOVA (site $\times$ type $\times$ location, sites serving as replicates within each combination of factor levels). Again, we dropped the interaction term when it was non-significant, but did a separate comparison of locations at each site type when the interaction was significant. We also tested for correlations among these variables across all sites/locations.

Studies of habitat relationships are necessarily multivariate (Reinert 1993) and typically involve methods such as Principal Components Analysis (PCA) and Discriminant Function Analysis (DFA). In comparing categories of habitats, such as we have in this study, two approaches are possible (Quinn and Keough 2002). One is the multivariate analysis of variance (MANOVA) approach embodied by Discriminant Function Analysis (DFA). A second is to do a Principal Components Analysis (PCA) of all groups combined and then compare the derived components among groups using univariate ANOVA. Although the two approaches do not produce identical results, they generally result in broadly similar patterns of group differences (Quinn and Keough 2002). Advantages of the PCA approach include ease of analysis of multiple derived components and straightforward post hoc comparisons of particular groups (Quinn and Keough 2002), so we used it here.
To avoid pseudo-replication, especially for variables for which only one measurement was made per location (see above), we used the reduced data set (i.e., means of the three transects treated as data) for multivariate analysis. Using the same variables as in the ANOVAs above, we subjected the data to PCA, examined each of the first three principal components for influence of the original variables, and then treated each of the principal components as variables in separate two-way ANOVAs (as above). We also used the first principal component (PC 1) as the independent variable in a logistic regression comparing sites/ locations known to be used by Contia vs. all other sites.

\section{Results}

Two-way ANOVAs using individual transect data as values yielded few differences attributable to location, although sites differed significantly for several variables. In comparisons of assigned vs. random locations for known site types, we found an effect only of rock cover, which was higher at assigned than at random locations $\left(\mathrm{F}_{1.34}=3.42, P=0.07\right)$. In cases of variables for which there was a significant interaction between site and location (extent of litter, slope of transect, coarse woody debris), differences between locations were significant at some sites, but not in any consistent direction.

For potential site types, assigned and random locations differed only in thick ground cover $\left(\mathrm{F}_{1.69}=38.8\right.$, $P=0.053$ ), which was higher in assigned locations. Sites again differed significantly for several variables and the interaction between site and location was significant for four variables (extent of litter, rock cover, light ground cover, shrub cover). Patterns from interactions again generally were indistinct, but for the three sites that differed significantly in rock cover, the value was higher at assigned than random locations; for three sites differing significantly in shrub cover, the value was lower at assigned locations.

Nested ANOVAs comparing assigned locations between known and potential site types showed only that known site types had lower soil depth $\left(\mathrm{F}_{1,29}=3.20\right.$, $P=0.08)$ and less coarse woody debris $\left(\mathrm{F}_{1,29}=7.45\right.$, $P=0.01)$ than potential site types. Again, there were significant differences among sites for some variables. Similar comparison of random locations between known and potential site types revealed only that rock cover was higher at known site types $\left(\mathrm{F}_{119}=3.15\right.$, $P=0.09$ ), with sites again varying significantly for some variables.

Two-way ANOVAs, using mean values (per 3 transects) as data (and all site type $\times$ location combinations, $n=52$ ), revealed more differences (Table 1). Overall (i.e., assigned and random locations considered together), known site types had shallower soil $\left(\mathrm{F}_{1.49}=2.92\right.$, $P=0.09)$, shallower litter $\left(\mathrm{F}_{1,49}=2.95, P=0.09\right)$, and higher rock cover $\left(\mathrm{F}_{1,49}=4.67, P=0.04\right)$ than 
TABLE 1. Statistical summary of main habitat variables by site type (known vs. potential) and location (assigned vs. random). Only variables that were significantly different in at least one analysis (see text) are shown. Individual data are means for 3 transects at each site type/location combination; shown in the table are mean (top row) and \pm standard deviation, minimum value - maximum value (bottom row) of these transect means.

\begin{tabular}{|c|c|c|c|c|}
\hline \multirow{2}{*}{$\begin{array}{l}\text { Site type } \\
\text { Location }\end{array}$} & \multicolumn{2}{|c|}{ Known } & \multicolumn{2}{|c|}{ Potential } \\
\hline & $\begin{array}{l}\text { Assigned } \\
(\mathrm{n}=16)\end{array}$ & $\begin{array}{c}\text { Random } \\
(\mathrm{n}=7)\end{array}$ & $\begin{array}{c}\text { Assigned } \\
(\mathrm{n}=15)\end{array}$ & $\begin{array}{l}\text { Random } \\
(\mathrm{n}=14)\end{array}$ \\
\hline \multirow[t]{2}{*}{ Rock Cover (m) } & 2.7 & 2.1 & 1.6 & 0.9 \\
\hline & $2.45,0-7.46$ & $2.24,0.02-6.03$ & $1.78,0.02-6.40$ & $1.04,0.01-3.11$ \\
\hline \multirow[t]{2}{*}{ Coarse Woody Debris (m) } & 0.1 & 0.6 & 0.4 & 0.5 \\
\hline & $0.18,0-0.71$ & $1.37,0-3.70$ & $0.43,0-1.71$ & $0.72,0-2.07$ \\
\hline \multirow[t]{2}{*}{ Thick Ground Cover (m) } & 0.6 & 0 & 0.3 & 0.03 \\
\hline & $0.96,0-3.50$ & $0,0-0$ & $0.56,0-1.61$ & $0.05,0-0.14$ \\
\hline \multirow[t]{2}{*}{ Shrub Cover $(\mathrm{m})$} & 1.8 & 2.3 & 1.8 & 3.5 \\
\hline & 1.83. $0-5.29$ & $1.42,0.41-4.00$ & $1.85,0-6.95$ & $3.04,0-9.95$ \\
\hline \multirow[t]{2}{*}{ Soil Depth $(\mathrm{cm})$} & 6.6 & 8.4 & 9.0 & 9.4 \\
\hline & $2.44,3.5-10.9$ & $3.58,3.6-13.2$ & $4.85,4.3-22.2$ & $4.30,2.7-17.0$ \\
\hline \multirow[t]{2}{*}{ Litter Depth $(\mathrm{cm})$} & 2.1 & 2.2 & 2.7 & 3.3 \\
\hline & $1.26,0-4.3$ & $1.46,1.0-5.3$ & $1.14,0.7-4.2$ & $2.23,0.7-8.7$ \\
\hline \multirow[t]{2}{*}{ Overhead Canopy (\%) } & 28.8 & 17.1 & 7.3 & 28.2 \\
\hline & $21.17,0-60.0$ & $22.15,0-50.0$ & $14.25,0-50.0$ & $21.6,0-50.0$ \\
\hline \multirow[t]{2}{*}{ Surrounding Canopy (\%) } & 25.4 & 21.1 & 19.1 & 35.1 \\
\hline & $12.39,2.5-52.5$ & $16.51,0-42.5$ & $14.74,0-46.3$ & $18.66,0-52.5$ \\
\hline \multirow[t]{2}{*}{ Transect Slope $\left(^{\circ}\right)$} & 13.0 & 15.4 & 11.2 & 7.7 \\
\hline & $7.76,0-28.33$ & $15.39,0-45.33$ & $9.56,0-27.67$ & $7.24,0.67-27.33$ \\
\hline
\end{tabular}

potential site types, on average. Assigned locations had more thick ground cover $\left(\mathrm{F}_{1.49}=4.15, P=0.047\right)$, less shrub cover $\left(\mathrm{F}_{1,49}=3.59, \stackrel{P}{P}=0.06\right)$, less overhead canopy cover (potential site types only, $\mathrm{F}_{1,27}=9.55$, $P=0.005$ ), less surrounding canopy cover (potential site types only, $\mathrm{F}_{1,27}=6.62, P=0.02$ ), and steeper transect slopes (potential site types only, $F_{1,27}=5.90$, $P=0.02$ ) than random locations, on average.

As expected, many of the variables above were significantly correlated over all site types/locations $(n=52$ in all cases). These included mean soil depth vs. mean litter depth $(\mathrm{r}=0.40, P=0.004)$, mean rock cover vs. mean litter depth $(\mathrm{r}=-0.29, P=0.04)$, mean soil depth vs. mean rock cover $(\mathrm{r}=-0.38, P=0.005)$ and overhead canopy cover vs. surrounding canopy cover (r $=0.58, P<0.0001$ ).

Direction (aspect) differed significantly among site type/location categories (Fisher's exact test, $P=0.004$ ). Thirteen known/assigned locations $(81 \%)$ faced south and the rest (3) all faced west, whereas only six (40\%) of potential/assigned locations faced south and another six faced east. Potential/random locations were particularly deviant from known/assigned, with eight (57\%) facing either north or east. These results were consistent with those from analysis via circular statistics (mean vectors: known assigned - 203.99 ; known random $-215.15^{\circ}$; potential assigned $-155.73^{\circ}$; potential random $-125.86^{\circ}$ ). Significant differences between site type/location categories were as follows: known assigned vs. potential assigned $-\mathrm{F}_{1,29}=4.27, P=0.05$; known assigned vs. potential random $-\mathrm{F}_{1,28}=7.21$, $P=0.01$; known random vs. potential assigned -
$\mathrm{F}_{1,20}=3.02, P=0.1$; known random vs. potential random $-\mathrm{F}_{1,19}=3.55, P=0.07$, although this last result may not be reliable because of a uniform distribution of points.

We ran PCA using various combinations of variables, dropping those that had low weights on PC 1. Results were broadly similar in all cases, but they were most clearly defined when we used mean rock cover, mean soil depth, mean surrounding canopy cover, and mean shrub cover as variables in the analysis. In that case, PC 1 accounted for $44 \%$ of the total variance and PC 2 and PC $323 \%$ and 20\%, respectively. This high cumulative percentage variance for the first three principal components suggests that they summarized the data efficiently (McGarigal et al. 2000). PC 1 was positively weighted by soil depth, surrounding canopy cover, and shrub cover, but negatively weighted by rock cover (Table 2 ).

Two-way ANOVAs on the PCs showed that PC 1 differed overall between both site types $\left(\mathrm{F}_{1.49}=4.19\right.$, $P=0.046)$ and locations $\left(\mathrm{F}_{1,49}=4.84, P=0.03\right)$. Known site types had lower average values of PC 1 than potential site types and assigned locations had lower values than random, consistent with the two-way ANOVAs performed above on the individual variables and with the signs of coefficients in PC 1 . Random locations had higher values of PC 2 than assigned locations, but only for potential site types $\left(\mathrm{F}_{1,27}=3.86\right.$, $P=0.06)$. Neither site types nor locations differed with respect to $\mathrm{PC} 3$.

Despite statistically interesting differences in PC 1 between site types and locations, differences overall 
TABLE 2. Summary of weights (coefficients) of four variables on first three principal components in analysis of habitat variables potentially influencing occurrence of Sharp-tailed Snakes. PC 1 accounts for 44\% of variance and PC 2 and PC $323 \%$ and $20 \%$, respectively.

\begin{tabular}{lccc}
\hline \hline Variable & PC 1 Coefficients & PC 2 Coefficients & PC 3 Coefficients \\
\hline Soil Depth & 0.497 & -0.591 & 0.346 \\
Surrounding Canopy Cover & 0.440 & 0.549 & 0.670 \\
Shrub Cover & 0.489 & 0.490 & -0.562 \\
Rock Cover & -0.566 & 0.331 & 0.339 \\
\hline \hline
\end{tabular}

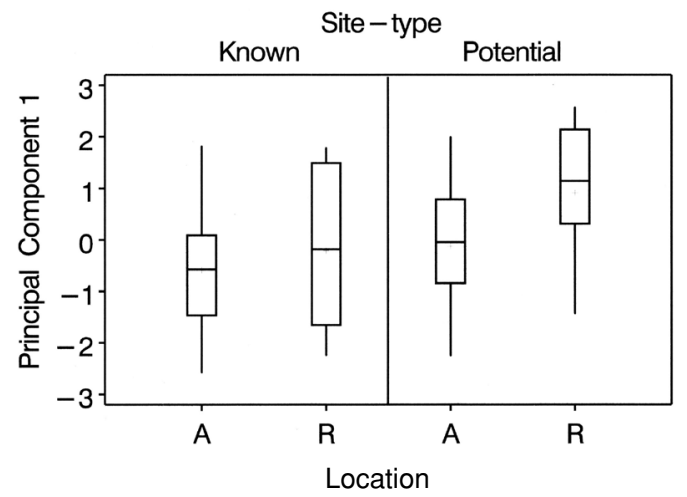

FIGURE 2. Box-and-whisker plots of values of principal component 1 by site type (known vs. potential) and location (actual, A, vs. random, R). Horizontal line in each box is median. Upper and lower boundaries of box (hinges) indicate quartiles $\left(25^{\text {th }}\right.$ and $75^{\text {th }}$ percentiles). Whiskers from box reach to the most extreme value that does not exceed 1.5 times the distance between the quartiles; $n=52$.

among the four site type/location combinations were not large (Figure 2). In fact, differences among these categories were graded rather than discrete. We therefore divided site type/location combinations into two categories, those known to be occupied by Sharp-tailed Snakes and those not. The resulting binomial variable was then regressed (logistic regression) against PC 1. The logistic model was a satisfactory fit to the data (Homer and Lemeshow test, $\chi_{8}^{2}=4.46, P=0.81$ ) and the relationship was significantly negative (Wald's $\chi^{2}{ }_{1}=4.25, P=0.04$; Figure 3 ). We also compared PC 1 of known/assigned locations successively, via logistic regression, to known/random, potential/ assigned and potential/random locations. The trend also was negative in each case, but significant (and strongly so) only in the last one. Thus, sites known to be occupied by Sharp-tailed Snakes differed from those not known to be occupied.

\section{Discussion}

The study of how and why animals occur in particular habitats has a long history in ecology and has been the subject of numerous reviews and syntheses (e.g.

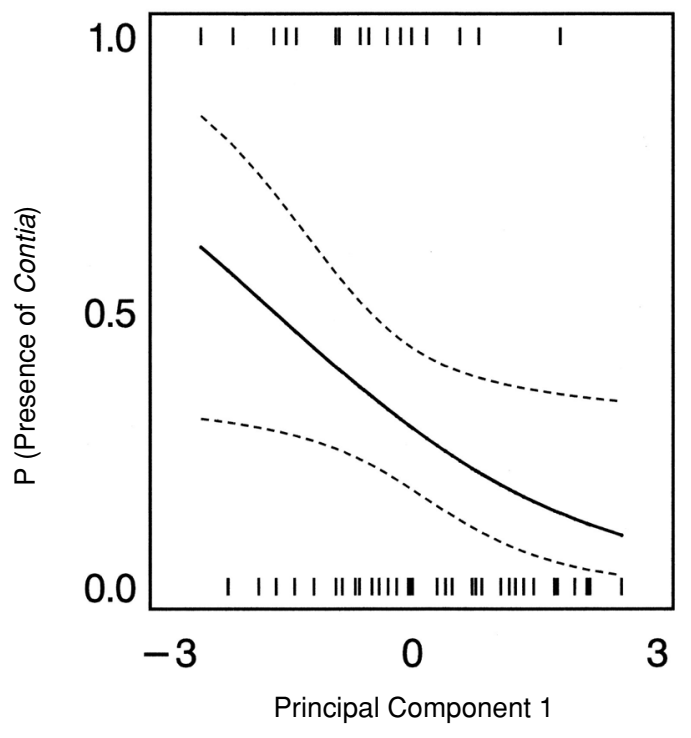

FIGURE 3. Logistic regression of presence(1)/absence(0) of Sharp-tailed Snakes vs. principal component 1 for all site type/location combinations. Absence implies "not recorded" rather than confirmed absence. Vertical lines are data points, solid line is predicted regression, and dashed lines are upper and lower $95 \%$ confidence limits on regression; $\mathrm{n}=52$.

Morse 1980; Gray and Craig 1991; Reinert 1993; Garshelis 2000). Habitat use by a species is a function not only of habitat selection based on resource requirements and physical factors such as temperature, but of other factors such as population density and the presence of competitors and predators (Huston 2002; Morris 2003). Thus, the habitats used by animals may not be those that are optimal for them in terms of fitness. In fact, it is even possible that some occupied habitats have negative implications for fitness (Van Horne 1983), for example if those habitats are sinks in a source-sink system (Pulliam 1988). Conversely, optimal habitats that could be used might not be occupied simply because the species' ability to disperse there is limited (Huston 2002). In short, the analysis and interpretation of habitat-use studies is fraught with difficulties (Garshelis 2000). In that light, this study 
is but a small first step towards understanding the habitat relationships of the Sharp-tailed Snake. It is further limited by its reliance on presence/absence (really presence/not recorded) data rather than data on abundance, or better, demographic performance (Pulliam 1988; Garshelis 2000). In terms of Garshelis' (2000) classification of methods, our approach is a variant of the site-attribute design, but with the added inclusion of predetermined potential sites for the species' occurrence.

Animals typically do not use their environments at random, but non-randomly, selecting some sites over others because of particular habitat and micro-habitat features. Thus, the mere demonstration that places used by a particular species are different from those not used is unremarkable by itself. For the conservationist or manager, however, determining which habitat characteristics are important is fundamental to preservation, restoration, or even creation of habitats.

What are the key features that describe suitable habitats for the Sharp-tailed Snake? The data collected in this study were highly variable and can only hint at differences between site types and locations that appear to be important. More detailed, longer-term work with larger samples would allow us to reach stronger conclusions, but this study was limited by the small number of sites at which the Sharp-tailed Snake is known to occur in southwestern British Columbia. It also was limited by the subjectivity with which potential sites were identified. For example, south-facing slopes are often favoured by snakes and this is reflected in the distribution of known and potential sites in this study. However, a Sharp-tailed Snake recently was found on a north-facing slope on Pender Island (D. Spalding, personal communication), suggesting that the species may occur in a wider range of conditions than previously thought. Currently, a more randomized approach to sampling sites for Sharp-tailed Snakes is under way to reduce this kind of bias, but we still have some way to go before we can convincingly move known and unknown unknowns to the fully known side of the ledger.

Aside from the necessary constraints of small numbers of known sites for Sharp-tailed Snakes, this study also might have been limited by failure to measure key environmental variables. For example, as is the case for other ectotherms, the ecology of Sharp-tailed Snakes is no doubt strongly influenced by temperature, which will affect the kinds of habitats and microhabitats they use at different times (Huey 1991; Reinert 1993; Blouin-Demers and Weatherhead 2001). Similarly, given the potential for desiccation in this small species, as well as a requirement for incubation sites for eggs, moisture also is likely to be an important physical factor. Therefore, cracks and openings for underground access and suitable sites for egg-laying or hibernation are potentially critical habitat features for these snakes. However, measuring subterranean access would be very difficult and we know nothing about the kinds of sites favoured by Sharp-tailed Snakes for egg deposition or for spending the winter. To deal adequately with temperature and moisture, we would need to measure them across all seasons and in multiple microhabitats per location simultaneously.

Despite these deficiencies, we found fairly clear indications that sites used by Sharp-tailed Snakes tend to be south-facing and to have relatively shallow soil and litter, relatively high rock cover, and relatively low shrub cover. Differences from randomly chosen sites emphasize this species' non-random use of habitats, but differences between locations actually used by snakes and those deemed to be potential habitat underline the subjectivity of visual habitat assessment. That said, this subjective approach based on field experience has proven effective. Although none of the potential sites used in this study have since yielded evidence of Sharp-tailed Snakes, two of the known sites were initially identified by $\mathrm{CE}$ as potential sites and another site designated as potential by $\mathrm{CE}$ after this study was completed has since turned out to be occupied by Sharp-tailed Snakes. Even so, quantitative measures for objective assessment of potential sites also would be valuable. Future work could focus on variables found to be important in this study and on others that we were unable to measure, such as those mentioned above as well as shrub height, tree density, soil composition, drainage, and type of bedrock.

Given the rarity of the Sharp-tailed Snake in British Columbia and the obvious difficulties in studying rare species in general, perhaps an alternative (or supplementary) approach would be to undertake comparative studies of this species in more southerly parts of its range where it is more widespread and more abundant. Extrapolating from a species' ecology in one part of its range to another distant one requires caution as there may be significant adaptive differences in different areas. For example, Sharp-tailed Snakes in California occupy a wide diversity of habitats (D. Wake, personal communication), most of which do not occur in British Columbia. Nonetheless, this approach might reveal fundamental species' characteristics that can be used to delineate more clearly the critical habitats required for conservation of the Sharp-tailed Snake in British Columbia.

\section{Acknowledgments}

We thank Laura Matthias and Michelle Masselink for showing us sites known to be occupied by Sharptailed Snakes and Andrea Pilski for assisting in the field. The Sharp-tailed Recovery Team offered useful help and advice and both David Wake and David Spalding provided us with important personal observations. We also thank various landowners for allowing access to their land: Pender Island - Don and Theresa Williams, Sylvia O'Reilly, Robert Dill, Jon Crawford, Pat and Ian Haugh; Saltspring Island Frances Hill and Dave Kerman, Sandra and Vince 
Knight, Leslie Northey, Mark and Brenda Haughley. The British Columbia government provided staff time. The views presented are those of the authors, not their respective agencies. The Endangered Species Recovery Fund (World Wildlife Fund, Canada) and the Habitat Conservation Trust Fund (BC) provided financial support.

Documents Cited (marked $*$ in text)

Capital Regional District. 2008. Natural areas atlas. http:// www.crd.bc.ca/maps/natural/atlas.htm (Accessed May, 2008).

COSEWIC. 2002. Canadian Species at Risk. Committee on the Status of Endangered Wildlife in Canada. http:// www.cosewic.gc.ca/eng/sct5/index_e.cfm (Accessed January, 2005).

Engelstoft, C., and K. Ovaska. 1998. Sharp-tailed snake study on the Gulf Islands and southern Vancouver Island, March - November 1997. Final report. Ministry of Environment, Lands and Parks, Nanaimo, British Columbia.

Meidinger, D. 1998. Field Manual for Describing Terrestrial Ecosystems. B.C. Ministry of Environment, Lands and Parks and B.C. Ministry of Forests. http://www.for.gov. bc.ca/hfd/pubs/Docs/Lmh/Lmh25.htm (Accessed August 2004).

\section{Literature Cited}

Blouin-Demers, G., and P. J. Weatherhead. 2001. Thermal ecology of black rat snakes (Elaphe obsoleta) in a thermally challenging environment. Ecology 82: 3025-3043.

Cook, S. F. 1960. On the occurrence and life history of Contia tenius. Herpetologica 16: 163-173.

Engelstoft, C., and K. Ovaska. 2000. Artificial cover-objects as a method for sampling snakes (Contia tenius and Thamnophis spp.) in British Columbia. Northwestern Naturalist 81: 35-43.

Engelstoft, C., K. Ovaska, and N. Honkanen. 1999. The harmonic direction finder: a new method for tracking movements of small snakes. Herpetological Review 30: 84-87.

Garshelis, D. L. 2000. Delusions in habitat evaluation: measuring use, selection, and importance. Pages 111-164 in Research techniques in animal ecology. Edited by L. Boitani and T. K. Fuller. Columbia University Press, New York. 442 pages.

Gray, R. D., and J. L. Craig. 1991. Theory really matters: hidden assumptions in the concept of "habitat requirements". Acta XX Congressus Internationalis Ornithologici: 2553-2560.

Huey, R. B. 1991. Physiological consequences of habitat selection. American Naturalist, Supplement 137: S91S115.

Huston, M. A. 2002. Introductory essay: critical issues for improving predictions. Pages 7-21 in Predicting species occurrences - issues of accuracy and scale. Edited by J. M. Scott, P. J. Heglund, M. L. Morrison, J. B. Haufler, M. G. Raphael, W. A. Wall and F. B. Samson. Island Press, Washington.

Leonard, W. P., D. Darda, and K. R. McAllister. 1996. Aggregations of sharptail snakes (Contia tenuis) on the east slope of the Cascade Range in Washington state. Northwestern Naturalist 77: 47-49.

Leonard, W. P., and M. A. Leonard. 1998. Occurrence of the sharptail snake (Contia tenuis) at Trout Lake, Klickitat County, Washington. Northwestern Naturalist 79: 75-76.

Leonard, W. P., and K. Ovaska. 1998. Contia Girard. Catalogue of American Amphibians and Reptiles 677.1677.7.

Leonard, W. P., and R. C. Stebbins. 1999. Observations of antipredator tactics of the sharp-tailed snake (Contia tenuis). Northwestern Naturalist 80: 74-77.

Matsuda, B. M, D. G. Green, and P. T. Gregory. 2006. Amphibians and reptiles of British Columbia. Handbook, Royal British Columbia Museum, Victoria, British Columbia. 266 pages.

McGarigal, K., S. Cushman, and S. Stafford. 2000. Multivariate statistics for wildlife and ecology research. Springer, New York. 283 pages.

Morris, D. W. 2003. Toward an ecological synthesis: a case for habitat selection. Oecologia 136: 1-13.

Morse, D. H. 1980. Behavioral mechanisms in ecology. Harvard University Press, Cambridge, Massaschusetts. 383 pages.

Ovaska, K., and C. Engelstoft. 1999. Contia tenuis (Sharptailed Snake) - defensive behavior. Herpetological Review 30: 168 .

Pulliam, H. R. 1988. Sources, sinks, and population regulation. American Naturalist 132: 652-661.

Quinn, G. P, and M. J. Keough. 2002. Experimental design and data analysis for biologists. Cambridge University Press, Cambridge. 537 pages.

Reinert, H. K. 1993. Habitat selection in snakes. Pages 201-240 in Snakes - ecology and behavior. Edited by R. A. Seigel and J. T. Collins. McGraw-Hill, Inc., New York. 414 pages.

Shermer, M. 2005. Rumsfeld's wisdom. Scientific American 293(3): 38.

Sokal, R. R., and F. J. Rohlf. 1981. Biometry, $2^{\text {nd }}$ ed. W. H. Freeman and Co., San Francisco. 859 pages.

Van Horne, G. 1983. Density as a misleading indicator of habitat quality. Journal of Wildlife Management 47: 893901.

Zar, J. H. 1984. Biostatistical Analysis, $2^{\text {nd }}$ ed. Prentice-Hall, Englewood Cliffs, NJ. 718 pages.

Received 11 April 2006

Accepted 20 May 2008 